Ärztliche Erfahrung beschränkt sich nicht auf medizinisches Fachwissen. Sie entsteht auch aus den mehr oder minder alltäglichen, heiter, ärgerlich oder nachdenklich stimmenden Erlebnissen mit Patienten, Kollegen und Mitarbeitern. Senden Sie uns Ihre Geschichte an: Brigitte.Moreano@springer.com. Für jeden veröffentlichten Text erhalten Sie bis zu 100 Euro.

\title{
Fortbildung im Tetrapack
}

— Nach Abschluss unserer Ausbildung in klassischer Homöopathie treffen wir uns noch in einer kleinen Guppe als QZ, regelmäßig reihum bei jedem, um interessante Weiterbildungen und unsere Patientenfälle zu besprechen und uns sozusagen gegenseitig zu supervidieren. Dabei sehen wir natürlich, z. B. beim gemeinsamen Mittagessen, auch immer die anderen Familienangehörigen und können so das Aufwachsen der Kinder der Kolleginnen miterleben.

Letztens saßen wir dann alle nach stundenlangem, intensivem fachlichem Austausch zum Mittagessen in Erwartung des Auflaufes um den Tisch, wo der achtjährigen Sohn seiner siebenjährigen Schwester gerade Apfelsaft aus dem Tetrapack einschenken wollte. Hilfsbereit und vorausschauend unfallverhütend wollten drei erwachsene Hände zugreifen, vor allem, weil der Junge den für ihn schweren Tetrapack "falsch herum" hielt, sodass sich die größere Hälfte der Packung unterhalb der Eingießöffnung befand. Aber selbstbewusst verbat er sich unsere Hilfe: „Das kann ich doch allein“, und erklärte uns darü-

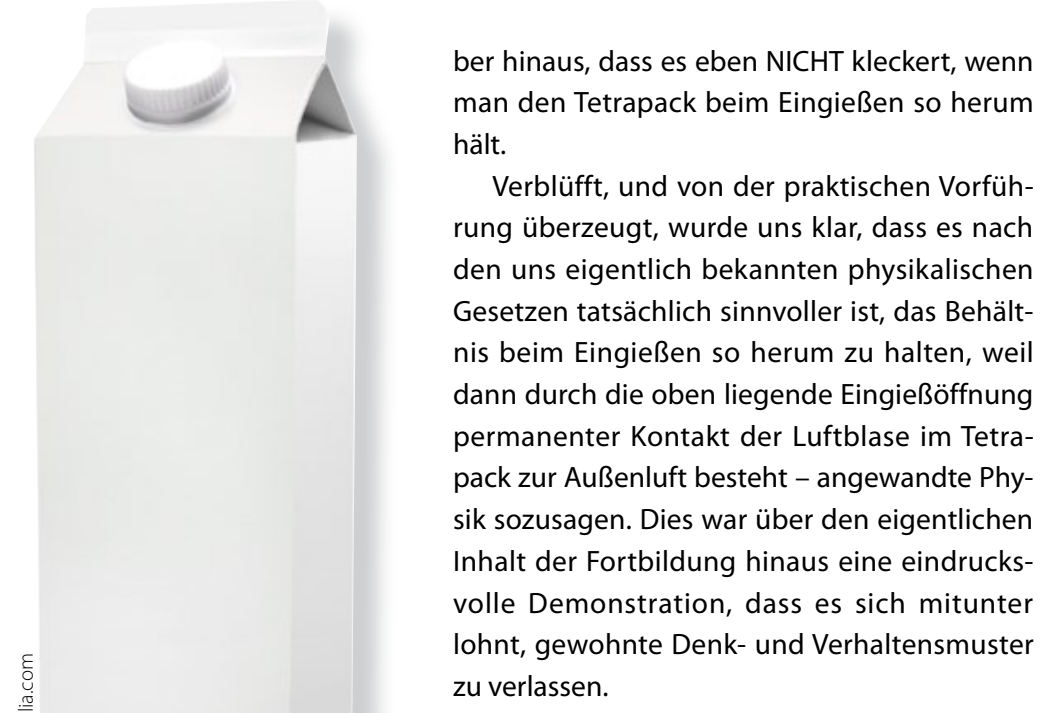

DR. MED. ANDREA LINSEL, LÜNEBURG =
Was hat ein Tetrapack mit

Homöopathie zu tun?

\section{Fremdsprachliches}

- Mit wehendem Kittel eilte ich vom Sprechzimmer zum Behandlungsraum. „Ah, la nostra dottora!", hörte ich eine italienische Patientin zu ihrer Bekannten sagen, "sempre fresca, sempre bella!"

Ich war äußerst geschmeichelt, dass sie mich "frisch und hübsch" fand, und bedankte mich mit einem freundlichen „Grazie, signora!" Sie wurde blutrot: „Sie haben mich verstanden?", fragte sie beschämt. „Das ist mir jetzt aber peinlich!“ Warum sollte ihr das unangenehm sein? Ich erklärte ihr lachend, dass so ein nettes Kompliment den Praxisalltag verschönere, und das ich mich ernsthaft darüber freute.

Kurz danach kam ich mit einem über Siebzigjährigen über Fremdsprachen ins Plaudern. „Ich kann Französisch“, bemerkte er, „nur mit der Sprache hapert es noch!“ Ich schaute ihn verblüfft an. Wusste er, was er da gesagt hatte? Vorsichtig forschte ich nach: Er wusste es nicht. Ich konnte mir die
Aufklärung nicht verkneifen, denn wer konnte schon wissen, wem er diesen Spruch sonst noch servieren würde. Nun wurde er tiefrot ...

Dr. med. Frauke Höllering, ARnsberg • 